\title{
Cryptocurrencies and asset pricing
}

\author{
Andros Gregoriou \\ Brighton Business School \\ Brighton University, Brighton \\ Moulsecoomb, BN2 4AT, UK \\ E-mail: a.gregoriou@,brighton.ac.uk
}

\begin{abstract}
We demonstrate that investors obtain abnormal returns by trading cryptocurrencies daily on the London Stock Exchange from 2014-2017. Excess returns persist once we account for systematic risk, size, value, momentum, profitability and investment. Investor abnormal returns in cryptocurrencies implies inefficiency.
\end{abstract}

Keywords: Cryptocurrencies; Capital Asset Pricing Model; London Stock Exchange; Efficiency.

JEL Classification: G12, G15 


\section{Introduction}

Over the last few years there has been great investor interest in the speculation of cryptocurrencies (Baek and Elbeck, 2015). Due to their increased importance in financial markets there has been an emerging literature on the efficiency of cryptocurrencies (Bariviera, 2017 and Brauneis and Mestel, 2018). Bariviera (2017) find evidence of inefficiency and Brauneis and Mestel (2018) observe a positive relationship between the liquidity of cryptocurrencies and stock market efficiency. Moore and Christin (2013) state the lack of regulation of cryptocurrency markets leads to frequent security breaches. Vasek and Moore (2015) discover threats of Ponzi schemes. Feder et al (2017) identify unlawful trading activity causing abnormal returns on the returns of cryptocurrencies. Moser et al (2013) suggest that it is difficult for the exchanges to know the identity of the investors in the trading of cryptocurrencies, leading to issues of money laundering. Huang et al (2014) detect the threat of mining botnets and Vasek et al (2016) pinpoint the possible theft of "brain" wallets. Gandal et al (2018) were able to directly analyze the impact of suspicious trading on the Bitcoin ecosystem. Using a unique dataset where each trade was matched to an individual investor, they discover that Bitcoin trades valued at 188 million USD were fraudulent. They conclude that suspicious trading was the most likely cause of the USD-BTC spike in late 2013, when the rate escalated from 150 USD to 1000 USD over a two month duration. ${ }^{1}$

In this paper we examine the impact of cryptocurrency returns on asset pricing models. If investors obtain significant returns on risky assets by investing in cryptocurrencies, then this explains both the speculation and the lack of efficiency in the cryptocurrency market. We conduct our empirical research on all stocks listed on the London Stock Exchange (LSE) over the period 2014-2017. We find overwhelming evidence that if cryptocurrency trades are included in a portfolio there is a positive impact on stock returns, even after we account for the influence of risk, value, size, momentum, profitability and investment. Our results highlight the inefficiency of of cryptocurrencies. The next section provides the details of how we construct risk adjusted returns in our econometric analysis. Section 3 describes the data used in our study. The empirical findings are presented in Section 4. Finally, Section 5 concludes.

\section{Risk Adjusted Returns}

In this section we explain how we will estimate abnormal time series performance of portfolios generated on the basis of cryptocurrency returns. We do this by estimating the four most common asset pricing models in the finance literature. First, we estimate Jensen's alpha from the single factor Capital Asset Pricing Model (CAPM) with the use of the following equation:

$$
R_{i, t}-R_{t}^{f}=\alpha_{i}+\beta_{i, M K T}\left(R_{m, t}-R_{t}^{f}\right)+\varepsilon_{i, t}
$$

Where $R_{i, t}$ is the return on portfolio $i$ on day $t, R_{t}^{f}$ is the risk free rate for day $t$ and $\left(R_{m, t}-R_{t}^{f}\right)$ is the excess market portfolio return on day t. Second, we compute the alpha from the Fama and French (1993) three factor model from the following equation:

\footnotetext{
${ }^{1}$ For a complete review of the cryptocurrency literature, see Bonneau et al (2015) for coverage of technical issues of Bitcoin and Bohme et al (2015) for a discussion of the design of Bitcoin.
} 


$$
R_{i, t}-R_{t}^{f}=\alpha_{i}+\beta_{i, M K T}\left(R_{m, t}-R_{t}^{f}\right)+\beta_{i, S M B} S M B_{t}+\beta_{i, H M L} H M L_{t}+\varepsilon_{i, t}
$$

where $\mathrm{SMB}_{\mathrm{t}}$ and $\mathrm{HML}_{\mathrm{t}}$ represent the size and value risk factors of the CAPM. Third, we derive the Carhart alpha by estimating the following four factor Carhart (1997) model:

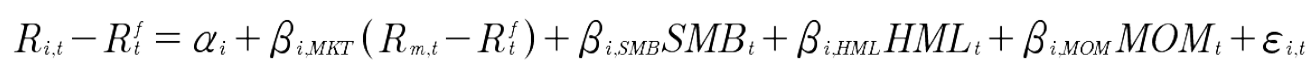

where $\mathrm{MOM}_{\mathrm{t}}$ denotes the momentum risk factor. Finally, we estimate the Fama and French (2015) five factor model alpha by running the following regression model:

$$
R_{i, t}-R_{t}^{f}=\alpha_{i}+\beta_{i, M K T}\left(R_{m, t}-R_{t}^{f}\right)+\beta_{i, S M B} S M B_{t}+\beta_{i \text { HML }} H M L_{t}+\beta_{i, M O M} M O M_{t}+\beta_{i, R M W} R M W_{t}+\beta_{i, C M A} C M A_{t}+\varepsilon_{i, t}
$$

where $\mathrm{RMW}_{\mathrm{t}}$ and $\mathrm{CMA}_{\mathrm{t}}$ is the profitability and investment risk factor respectively. In order to eliminate potential errors in variables we estimate the alphas for all equations with the use of the Generalized Method of Moments (GMM) estimator. The GMM is estimated with NeweyWest standard errors corrected for heteroscedasticity and autocorrelation.

\section{Data}

We collect daily data on all common stocks listed on the LSE for the period from January 2014 to December 2017, in order to match the data on cryptocurrencies which is provided by coinmarketcap.com. Following Brauneis and Mestel (2018) we collect data for the ten largest cryptocurrencies with respect to trading volume over the time period of our dataset. Following previous research on the LSE (see among others, Florackis et al, 2011) we include all listed and dead stocks in order to avoid survivorship bias in the data. Like prior UK stock market studies we exclude unit trusts, investment trusts and ADRs. We also eliminate firms with market value of less than $£ 10$ million in order to reduce the influence of outliers on our econometric results.

For the estimation of the asset pricing models explained in equations 1-4 we are required to construct the size, value, momentum, profitability and investment risk factors. For the size factor, we sort all listed stocks according to their market value at day t-1 and we assign the highest $30 \%$ (value weighted) to the "Big size" portfolio and the smallest $30 \%$ to the "Small size" portfolio. The difference of the returns between these two portfolios at day $t$ gives us the size factor return $\left(\mathrm{SMB}_{\mathrm{t}}\right)$. For the momentum factor we rank all available stocks at day $\mathrm{t}-1$ according to their returns from day t-13 to t-2. The top 30\% (value weighted) are classified as the 'Winners' and the bottom $30 \%$ as the 'Losers'. The deviation of their daily returns at day $\mathrm{t}$ is defined as the momentum factor return $\left(\mathrm{MOM}_{\mathrm{t}}\right)$.

For the profitability factor, we sort all listed stocks according to their profitability at day t-1 and we assign the highest 30\% (value weighted) to the "highly Profitable" portfolio and the smallest $30 \%$ to the "Weak Profitability" portfolio. The difference of the returns between these two portfolios at day $t$ gives us the profitability factor return $\left(\mathrm{RMW}_{\mathrm{t}}\right)$. For the investment factor, we sort all listed stocks according to their investment at day $\mathrm{t}-1$ and we assign the highest $30 \%$ (value weighted) to the "high Investment" portfolio and the smallest 30\% to the "Low Investment" portfolio. The difference of the returns between these two portfolios at day t gives 
us the investment factor return $\left(\mathrm{CMA}_{t}\right)$. Following Cuthbertson et al (2008), we compute the value factor $\left(\mathrm{HML}_{\mathrm{t}}\right)$ as the spread between the daily returns of the MSCI UK Growth and the MSCI UK Value indices. Finally, we use the FTSE All Share as the market index and the daily return on the 1-month UK interbank rate as the risk-free rate.

Having estimated the returns on each of the ten largest cryptocurrencies on each trading day over the sample period, we construct decile portfolios sorting the available shares on the basis of these two statistical measures. Portfolio 1 (P1) contains the shares with the lowest cryptocurrency returns, while Portfolio 10 (P10) contains the shares with the highest cryptocurrency returns. We calculate value-weighed portfolio returns in our econometric analysis as they give a more accurate description of the data than equally-weighed portfolios.

\section{Empirical results}

In this section we report the econometric analysis for the value weighted portfolios constructed on the basis of cryptocurrency returns, for each of the ten largest cryptocurrencies. Table 1 displays the risk adjusted time series performance of the spread strategy, that goes long the shares with the highest cryptocurrency returns and goes short the shares with the lowest cryptocurrency returns (P10-P1). For each of the ten cryptocurrencies in our sample we provide strong evidence of a positive and significant Jensen's alpha coefficient, once we account for the influence of risk, value, size, momentum, profitability and investment. It is not surprising that the spread strategy estimated by P10-P1 of Bitcoin exhibits the highest annualized return of all the cryptocurrencies, given that it is the most well known and heavily traded. In particular, the Bitcoin spread strategy P10-P1 generates a significant excess performance of $11.23 \%$ per annum ( $t$ value of 3.01) under the single factor CAPM. 10.53\% per annum ( $t$ value of 2.87) under the Fama and French three factor model which includes size and value as additional risk factors in the CAPM. 9.12\% per annum ( $\mathrm{t}$ value of 2.44) under the Carhart four factor model which includes size, value and momentum as additional risk factors in the CAPM. $6.76 \%$ per annum ( $\mathrm{t}$ value of 2.17) under the Fama and French five factor model which includes size, value, momentum, profitability and investment as additional risk factors in the CAPM.

Our results provide strong evidence that individuals can obtain excess returns on the LSE by investing in cryptocurrencies. The abnormal returns on cryptocurrencies continue to persist once we account for commonly used risk factors in asset pricing such as systematic risk, size, value, momentum, profitability and investment.

\section{[INSERT TABLE 1 HERE]}

\section{Conclusion}

In this paper we examine if individuals can obtain abnormal returns on the stock exchange by investing in cryptocurrencies. Using daily data on all LSE listed securities from 2014-2017, we provide convincing econometric evidence that investors obtain abnormal returns by trading cryptocurrencies once we account for systematic risk, size, value, momentum, profitability and investment. Our findings show that investors obtain excess returns on the LSE by speculating in cryptocurrencies, suggesting that they are inefficient. It would be fascinating to observe if the abnormal returns obtained by investors are as a result of fraudulent trading. In order to 
accomplish this, we require data on individual trades so we could replicate the analysis conducted by Gandal et al (2018). This is a very interesting avenue for future research. ${ }^{2}$

\footnotetext{
${ }^{2}$ We would like to thank an anonymous referee for suggesting this point.
} 


\section{References}

Baek, C. and Elbeck, M., 2015. Bitcoins as an investment or speculative vehicle? A first look. Applied Economics Letters, 22(1), pp.30-34.

Bariviera, A.F., 2017. The inefficiency of Bitcoin revisited: A dynamic approach. Economics Letters, 161, pp.1-4.

Böhme, R., Christin, N., Edelman, B. and Moore, T., 2015. Bitcoin: Economics, technology, and governance. Journal of Economic Perspectives, 29(2), pp.213-38.

Bonneau, J., Miller, A., Clark, J., Narayanan, A., Kroll, J.A. and Felten, E.W., 2015, May. Sok: Research perspectives and challenges for bitcoin and cryptocurrencies. In Security and Privacy (SP), 2015 IEEE Symposium on (pp. 104-121). IEEE.

Brauneis, A. and Mestel, R., 2018. Price discovery of cryptocurrencies: Bitcoin and beyond. Economics Letters, 165, pp.58-61.

Carhart, M.M., 1997. On persistence in mutual fund performance. The Journal of finance, 52(1), pp.57-82.

Cuthbertson, K., Nitzsche, D. and O'Sullivan, N., 2008. UK mutual fund performance: Skill or luck?. Journal of Empirical Finance, 15(4), pp.613-634.

Fama, E.F. and French, K.R., 1993. Common risk factors in the returns on stocks and bonds. Journal of financial economics, 33(1), pp.3-56.

Fama, E.F. and French, K.R., 2015. Incremental variables and the investment opportunity set. Journal of Financial Economics, 117(3), pp.470-488.

Feder, A., Gandal, N., Hamrick, J.T. and Moore, T., 2018. The impact of DDoS and other security shocks on Bitcoin currency exchanges: Evidence from Mt. Gox. Journal of Cybersecurity, 3(2), pp.137-144.

Florackis, C., Gregoriou, A. and Kostakis, A., 2011. Trading frequency and asset pricing on the London Stock Exchange: Evidence from a new price impact ratio. Journal of Banking \& Finance, 35(12), pp.3335-3350.

Gandal, N., Hamrick, J.T., Moore, T. and Oberman, T., 2018. Price manipulation in the Bitcoin ecosystem. Journal of Monetary Economics, 95, pp.86-96.

Huang, D.Y., Dharmdasani, H., Meiklejohn, S., Dave, V., Grier, C., McCoy, D., Savage, S., Weaver, N., Snoeren, A.C. and Levchenko, K., 2014, February. Botcoin: Monetizing Stolen Cycles. In NDSS.

Moore, T. and Christin, N., 2013, April. Beware the middleman: Empirical analysis of Bitcoin-exchange risk. In International Conference on Financial Cryptography and Data Security (pp. 25-33). Springer, Berlin, Heidelberg. 
Moser, M., Bohme, R. and Breuker, D., 2013, September. An inquiry into money laundering tools in the Bitcoin ecosystem. In eCrime Researchers Summit (eCRS), 2013 (pp. 1-14).

IEEE.

Vasek, M. and Moore, T., 2015, January. There's no free lunch, even using Bitcoin: Tracking the popularity and profits of virtual currency scams. In International conference on financial cryptography and data security (pp. 44-61). Springer, Berlin, Heidelberg.

Vasek, M., Bonneau, J., Ryan Castellucci, C.K. and Moore, T., 2016. The Bitcoin brain drain: a short paper on the use and abuse of bitcoin brain wallets. Financial Cryptography and Data Security, Lecture Notes in Computer Science. Springer. 


\section{TABLES}

\section{TABLE 1. Alphas of value-weighted Cryptocurrency portfolios}

This table reports the abnormal performance of the ten value-weighted cryptocurrency portfolios for the ten most heavily traded cryptocurrencies over the time period, of January 2014 to December 2017. All returns on shares traded on the London Stock Exchange are sorted into one of the ten portfolios on a daily basis. P1 is the decile portfolio containing the shares of with the lowest cryptocurrency returns and P10 with the highest cryptocurrency returns. P10-P1 is defined as the spread between portfolio P10 and Portfolio P1. Portfolios are rebalanced on a daily basis. CAPM alpha is the annualized alpha estimate derived from the Capital Asset Pricing Model. FamaFrench three factor alpha is the annualized alpha estimate derived from the Fama-French three factor model. Carhart four factor alpha is the annualized alpha estimate derived from the Carhart four factor model. FamaFrench five factor alpha is the annualized alpha estimate derived from the Fama-French five factor model. $t$ statistics are presented in brackets, $* * *$ and $* *$ implies statistical significance at the $5 \%$ and $1 \%$ level respectively.

\begin{tabular}{|c|c|c|c|c|}
\hline P10-P1 & $\begin{array}{c}\text { CAPM alpha } \\
(\% \text { p.a.) }\end{array}$ & $\begin{array}{c}\text { Fama-French } \\
\text { three factor } \\
\text { alpha (\% p.a.) }\end{array}$ & $\begin{array}{c}\text { Carhart alpha } \\
\text { (\% p.a.) }\end{array}$ & $\begin{array}{c}\text { Fama-French } \\
\text { five factor alpha } \\
\text { (\% p.a.) }\end{array}$ \\
\hline Bitcoin & $11.23(3.01)^{* * *}$ & $10.53(2.87)^{* * *}$ & $9.12(2.44)^{* *}$ & $6.76(2.17)^{* *}$ \\
\hline Ethereum & $6.89(2.26)^{* *}$ & $3.36(2.24)^{* *}$ & $2.84(2.07)^{* *}$ & $1.91(2.26)^{* *}$ \\
\hline Ripple & $8.23(2.98)^{* * *}$ & $5.32(2.62)^{* * *}$ & $3.11(2.29)^{* *}$ & $2.81(2.11)^{* *}$ \\
\hline Dash & $6.46(2.65)^{* * *}$ & $4.57(2.31)^{* *}$ & $3.89(2.09)^{* *}$ & $3.01(2.00)^{* *}$ \\
\hline Litecoin & $10.01(3.22)^{* * *}$ & $7.34(2.94)^{* * *}$ & $6.66(2.73)^{* * *}$ & $4.01(2.43)^{* *}$ \\
\hline Monero & $8.43(3.42)^{* * *}$ & $7.12(3.01)^{* * *}$ & $6.01(3.03)^{* * *}$ & $4.21(2.78)^{* * *}$ \\
\hline Nem & $7.01(3.22)^{* * *}$ & $6.34(2.87)^{* * *}$ & $5.01(2.74)^{* * *}$ & $3.10(2.65)^{* * *}$ \\
\hline Stellar & $6.23(2.98)^{* * *}$ & $5.32(2.62)^{* * *}$ & $3.49(2.39)^{* *}$ & $2.31(2.13)^{* *}$ \\
\hline Bitshares & $5.43(2.65)^{* * *}$ & $4.45(2.31)^{* *}$ & $2.37(2.16)^{* *}$ & $1.65(2.29)^{* *}$ \\
\hline Monacoin & $4.76(2.17)^{* *}$ & $3.01(2.16)^{* *}$ & $2.02(2.06)^{* *}$ & $1.04(2.03)^{* *}$ \\
\hline
\end{tabular}

